\title{
Genetic susceptibility to multiple sclerosis in the Shanghai Chinese is not linked to the myelin basic protein gene microsatellite
}

\author{
M A Kelly, Y Zhang, C H Mijovic, K-Y Chou, A H Barnett, D A Francis
}

Department of

Medicine,

University of

Birmingham and

Birmingham

Heartlands Hospital,

Birmingham

M A Kelly

C H Mijovic

A H Barnett

Shanghai Institute of Immunology,

Shanghai Second

Medical University,

Shanghai,

Peoples Republic of

China

Y Zhang

K-Y Chou

Regional Centre for Neurology,

Queen Elizabeth

Hospital,

Birmingham

D A Francis

Correspondence to:

Dr M A Kelly,

Department of Medicine,

Clinical Research Block,

Queen Elizabeth Hospital,

Queen Elizabeth Hospital,

Edgbaston,

Accepted for publication

10 January 1995

\begin{abstract}
Aim-To investigate the role of myelin basic protein (MBP) gene polymorphisms in determining susceptibility to multiple sclerosis in a Shanghai Chinese population.

Methods-Forty seven unrelated patients with multiple sclerosis and 94 healthy control subjects were included in the study. Genomic DNA was extracted from peripheral blood lymphocytes and amplified using the polymerase chain reaction to characterise two adjacent tetranucleotide repeats ([ATGG $]_{12}$ and [TGGA $]_{9}$ ) located $5^{\prime}$ to exon 1 of the MBP gene.

Results-Two polymorphic loci were identified: locus $A$, comprising both repeats, and locus $B$, comprising the $[A T G G]_{12}$ repeat only. Nine allelic variants were identified at locus $A$ and six at locus $B$, ranging from 212 to 244 and 122 to 146 base pairs, respectively. The 244 base pair allele at locus $A$ has not been reported before. The allele frequencies observed in the controls differed from those seen in normal white populations.

Conclusions-The present study demonstrates a race specific pattern of allelic distribution within the tetranucleotide repeat of the MBP gene. Further studies are needed to fully elucidate the role of the MBP gene in inherited susceptibility to multiple sclerosis.

(f Clin Pathol: Mol Pathol 1995;48:M111-M112)
\end{abstract}

Keywords: Multiple sclerosis, Shanghai Chinese, myelin basic protein gene, polymorphism.

Multiple sclerosis is a chronic inflammatory disease of the central nervous system, characterised by destruction of the myelin sheath and gliosis. Both environmental and genetic factors are implicated in disease susceptibility, although the precise identity of these components is unknown. Inherited predisposition to multiple sclerosis has been mapped to the HLA complex located on chromosome 6 . In north European Caucasian populations the disease is strongly associated with alleles of the DRB1*1501.DQA1*0102.DQB1*0602 haplotype. Segregation studies in multiplex families with multiple sclerosis, however, suggest that non-HLA genes may also play a significant role in disease development. ${ }^{1}$

Multiple sclerosis is a rare disease in the Chinese, with an approximate prevalence of
0.88 per $10^{5}$ population. $^{2}$ Previous investigations of disease susceptibility determinants in this race have demonstrated no consistent association between multiple sclerosis and HLA-DR or -DQ alleles. ${ }^{23}$ The nonHLA loci may play a more important role in the aetiology of the disease in the Chinese. This ethnic group may therefore be valuable in the investigation of non-HLA encoded susceptibility.

The aetiology of multiple sclerosis is unknown but it may involve an autoimmune response with myelin basic protein (MBP) as a putative target antigen. This concept is based on similarities between multiple sclerosis and experimental allergic encephalomyelitis, which can be induced in rodents by immunisation with MBP or transfer of MBP specific T cells. ${ }^{4}$ Polymorphisms of a tetranucleotide repeat region, located $5^{\prime}$ to the MBP gene on chromosome 18, have been implicated in susceptibility to multiple sclerosis in Canadian and Finnish populations. ${ }^{5}$ The Finnish study ${ }^{6}$ supported genetic linkage with this locus in familial disease. In both cases, however, a low resolution technique was used to type this complex polymorphism and it is possible that different allelic variants were assigned the same fragment size. An improved method has been reported, permitting the analysis of two perfect tetranucleotide repeat motifs at the $5^{\prime}$ end of the complex repeat. ${ }^{7}$ We have used this technique to investigate the role of MBP gene polymorphisms in determining susceptibility to multiple sclerosis in a Shanghai Chinese population.

\section{Methods}

Forty seven unrelated patients with multiple sclerosis and 94 healthy control subjects were recruited from Shanghai and the neighbouring provinces of Zhejiang and Jiangsu. All the subjects were of Han nationality. Genomic DNA was prepared from peripheral blood lymphocytes from all the subjects. The primers described by Polymeropoulos $e t a l^{7}$ were used to amplify (using the polymerase chain reaction) two adjacent perfect tetranucleotide repeats ([ATGG $]_{12}$ and $[\text { TGGA }]_{9}$ ) located $5^{\prime}$ to exon 1 of the MBP gene. The forward primer was $5^{\prime}$-labelled with ${ }^{32} \mathrm{P}$ using $\mathrm{T}_{4}$ polynucleotide kinase. The amplified products were separated on a $6 \%$ denaturing acrylamide gel at 40 watts for three hours, along with radiolabelled size markers and a DNA sequencing ladder prepared using the TA cloning kit (Invitrogen, 
Table 1 Allele frequencies for the polymorphic $A$ locus of the MBP gene in Chinese patients with multiple sclerosis and control subjects

\begin{tabular}{lll}
\hline & $\begin{array}{l}\text { Multiple sclerosis } \\
\text { patients }\end{array}$ & $\begin{array}{l}\text { Control subjects } \\
N=184)\end{array}$ \\
Allele & $(N=92)$ & $n(\%)$ \\
$(b p)$ & $n(\%)$ & $17(9 \cdot 2)$ \\
\hline 212 & $11(12 \cdot 0)$ & $5(2 \cdot 7)$ \\
216 & $7(7 \cdot 6)$ & $30(16 \cdot 3)$ \\
220 & $21(2 \cdot .8)$ & $15(8 \cdot 2)$ \\
224 & $4(4 \cdot 3)$ & $21(11 \cdot 4)$ \\
228 & $8(8 \cdot 8)$ & $47(25 \cdot 5)$ \\
232 & $25(27 \cdot 2)$ & $34(18 \cdot 5)$ \\
236 & $10(10 \cdot 9)$ & $15(8 \cdot 2)$ \\
240 & $5(5 \cdot 4)$ & $0(0)$ \\
244 & $1(1 \cdot 2)$ & $(1 \cdot 2)$ \\
\hline
\end{tabular}

Overall $\chi^{2}$ for locus $A=11 \cdot 87, D F=8, p>0 \cdot 1 ; b p=$ base pairs.

Table 2 Allele frequencies for the polymorphic $B$ locus of the MBP gene in Chinese patients with multiple sclerosis and control subjects

\begin{tabular}{lll}
\hline & $\begin{array}{l}\text { Multiple sclerosis } \\
\text { patients } \\
(n=94)\end{array}$ & $\begin{array}{l}\text { Control subjects } \\
(n=184) \\
n(\%)\end{array}$ \\
$\begin{array}{l}\text { Allele } \\
(b p)\end{array}$ & $n(\%)$ & $34(18 \cdot 5)$ \\
\hline 122 & $27(28 \cdot 7)$ & $0(0)$ \\
126 & $0(0)$ & $19(10 \cdot 3)$ \\
130 & $11(11 \cdot 7)$ & $31(16 \cdot 8)$ \\
134 & $11(11 \cdot 7)$ & $70(38 \cdot 0)$ \\
138 & $35(37 \cdot 2)$ & $27(14 \cdot 7)$ \\
142 & $8(8 \cdot 5)$ & $2(1 \cdot 1)$ \\
146 & $2(2 \cdot 1)$ & \\
\hline
\end{tabular}

Overall $\chi^{2}$ for locus $B=6 \cdot 74, D F=6, p>0 \cdot 1 ; b p=$ base pairs.

Abingdon, UK). The alleles were detected by autoradiography.

\section{Results}

Two polymorphic loci were identified: locus A, comprised of both repeat motifs, and locus $B$, representing the $[A T G G]_{12}$ repeat only. Nine allelic variants were distinguished at locus $\mathrm{A}$ and six at locus $B$, ranging in size from 212 to 244 base pairs and 122 to 146 base pairs, respectively. The 244 base pair allele at locus A has not been reported previously. The distribution of these alleles among the Chinese patients with multiple sclerosis and control subjects is presented in tables 1 and 2 . The allele frequencies observed in the control group differed significantly from those reported previously in normal white populations $(p<0.001$ for each locus based on an overall $\chi^{2}$ test). ${ }^{78}$ There was no significant association between multiple sclerosis and any of the alleles detected in our Chinese subjects.

\section{Discussion}

The present study demonstrates a race specific pattern of allelic distribution within the tetranucleotide repeat region of the MBP gene. None of the polymorphisms correlated with susceptibility to multiple sclerosis in the Chinese. This supports the findings of Graham et $a l,{ }^{8}$ who demonstrated no association of multiple sclerosis with these alleles in a population of sporadic patients from Northern Ireland. Recent studies of multiplex families with multiple sclerosis have also concluded that there is no genetic linkage between the disease and the MBP alleles. ${ }^{910}$ Our data do not support the studies of the Finnish and Canadian populations, which implicated the MBP locus in genetic predisposition to multiple sclerosis. ${ }^{56}$ It is possible that the associations observed in these studies reflect population specific disease markers. Alternatively, the associations may be secondary to polymorphisms lying outside the two loci investigated in the present study. The method of Polymeropoulos et $a l^{7}$ enabled us to investigate a 250 base pair portion of the total 994 base pair complex repeat. It is possible that polymorphisms exist within the remaining 740 base pair region and these may account for the associations observed between the MBP microsatellite and multiple sclerosis. Further characterisation of the polymorphisms present in the whole tetranucleotide repeat region is necessary to verify the disease associations observed in these populations and to fully elucidate the role of the MBP gene in inherited susceptibility to multiple sclerosis.

This work was supported by the Multiple Sclerosis Society of Great Britain and Northern Ireland. We are grateful for additional support from the West Midlands Regional Health Authority, Lilly Industries UK and the Wellcome Trust. We thank Drs W-Z Yu of Ruijin Hospital, Y Cai of Renji Hospital, Z Drs W-Z Yu of Ruijin Hospital, Y Cai of Renji Hospital, Z
Ying of the Second Hospital of Zhejiang and PW Chou of Ying of the Second Hospital of Zhejiang and PW Chou of Nantong Medical University for recruiting the patients with
multiple sclerosis. We are also grateful to Dr Y Yang and $\mathrm{Mr}$ multiple sclerosis. We are also grateful to Dr Y Yang and Mr the DNA from the blood samples.

1 Ho HZ, Tiwari JL, Haile RW, Terasaki PI, Morton NE. HLA-linked and unlinked determinants of multiple sclerosis. Immunogenetics 1982;15:509-17.

2 Hawkins BR, Yu YL, Woo E, Huang CY. No apparent association between HLA and multiple sclerosis in southern Chinese. $\Im$ Neurol Neurosurg Psychiatry 1988;51:443-5.

3 Kelly MA, Zhang Y, Penny MA, Jacobs KH, Cavan DA Mijovic $\mathrm{CH}$, et al. Genetic susceptibility to multiple sclerosis in a Shanghai Chinese population; the role of HLA class II genes. Hum Immunol 1995; in press.

4 Pettinelli CB, McFarlin DE. Adoptive transfer of experimental allergic encephalomyelitis in SJL/J mice after in vitro activation of lymph node cells by myelin basic protein: requirements for Lyt $1^{+} 2^{-} \mathrm{T}$ lymphocytes. $\mathcal{F} \mathrm{Im}-$ protein: requirements for

5 Boylan KB, Takahashi N, Paty DW, Sadovnick AD, Diamond M, Hood LE, et al. DNA length polymorphism $5^{\prime}$ to the myelin basic protein gene is associated with multiple sclerosis. Ann Neurol 1990;27:291-7.

6 Tienari PJ, Wikstrom J, Sajantila A, Palo J, Peltonen L. Genetic susceptibility to multiple sclerosis linked to myelin basic protein gene. Lancet 1992;340:987-91.

7 Polymeropoulos MH, Xiao H, Merril CR: Tetranucleotide repeat polymorphism at the human myelin basic protein gene (MBP). Hum Mol Genet 1992;1:658.

8 Graham CA, Kirk CW, Nevin NC, Droogan AG, Hawkins SA, McMillan SA, et al. Lack of association between myelin basic protein gene microsatellite and multiple sclermyelin basic protein gene micro

9 Rose J, Gerken S, Lynch S, Pisani P, Varvil T, Otterud B, et al. Genetic susceptibility in familial multiple sclerosis not linked to the myelin basic protein gene. Lancet 1993 341:1179-81.

10 Wood NW, Holmans P, Clayton D, Robertson N, Compston DAS. No linkage or association between multiple sclerosis and the myelin basic protein gene in affected sibling pairs. $\Im$ Neurol Neurosurg Psychiatry 1994;57:1191-4. 